\title{
Providing Suitable Pediatric Formulations for Canadian Children: A Call for Action
}

\author{
Catherine Litalien, Julie Autmizguine, Antoine Carli, Denis Giroux, Denis Lebel, Jean-Marie Leclerc, \\ Yves Théorêt, Andrea Gilpin, and Sophie Bérubé
}

Can J Hosp Pharm. 2020;73(4):247-56

\begin{abstract}
Background: Many medications given to children have no commercially available, age-appropriate formulations. This leads to manipulation of dosage forms designed for adults (compounding), which can result in an increased risk of dosing errors and adverse events, lack of medication adherence because of taste issues, and suboptimal dosing with therapeutic failure.
\end{abstract}

Objectives: To determine which drugs required compounding for oral administration to children in a Canadian hospital and, for each compounded drug, to determine whether it was available as licensed oral pediatric formulations in the United States or the European Union.

Methods: Drugs requiring compounded liquid formulations for oral administration, dispensed from January 1 to December 31, 2015, at a Canadian university-affiliated tertiary pediatric hospital, and prepared in a quantity exceeding $0.5 \mathrm{~L}$ per year, were retrospectively identified. The online drug databases of Health Canada, the US Food and Drug Administration, the European Medicines Agency (EMA), and the UK Medicines and Healthcare Products Regulatory Agency were searched to determine the availability of child-friendly oral formulations for these drugs. The regulatory status in each jurisdiction was also compared. For licensed formulations with potential concerns about excipient safety, EMA guidelines for sorbitol, propylene glycol, ethanol, and sodium benzoate were used to determine pediatric suitability.

Results: Of the 56 compounded drugs investigated, 27 (48\%) had a suitable commercialized child-friendly formulation available outside Canada. Overall, these drugs had been on the Canadian market for a median of 35 years, and almost half (27 [48\%]) had a pediatric indication in Canada.

Conclusions: Canada is lagging behind the United States and the European Union in ensuring availability of and access to suitable pediatric formulations. Potential explanations for this gap include small market size, regulatory uncertainties, and reimbursement shortcomings. Steps must be taken to implement pediatric-sensitive regulations and incentives, as well as reimbursement policies, to address these unmet needs.

Keywords: compounding, child-friendly medicines, pediatric oral medicines

\section{RÉSUMÉ}

Contexte : Plusieurs médicaments administrés aux enfants ne sont pas disponibles commercialement sous une forme pharmaceutique adaptée à leur âge. Ceci entraîne une manipulation des formes destinées aux adultes (préparation magistrale) et peut conduire à une augmentation du risque d'erreurs de dosage et d'effets indésirables, un manque d'observance médicamenteuse secondairement à des problèmes de goût, et un dosage sous-optimal associé à des échecs thérapeutiques.

Objectifs : Définir les médicaments qui exigent une préparation magistrale pour être administrés par voie orale aux enfants dans un hôpital canadien et, pour chaque médicament faisant l'objet d'une préparation magistrale, déterminer s'il est disponible sous une forme pharmaceutique orale autorisée pour les enfants aux États-Unis ou dans I'Union européene.

Méthodes : Les médicaments nécessitant des préparations magistrales liquides pour administration orale, distribués entre le $1^{\text {er }}$ janvier et le 31 décembre 2015 dans un hôpital de soins pédiatriques tertiaires affilié à une université canadienne et dont la quantité préparée était supérieure à $0.5 \mathrm{~L}$ par an, ont été déterminés rétrospectivement. Les bases de données en ligne de médicaments de Santé Canada, de la Food and Drug Administration américaine, de l'Agence européenne des médicaments (AEM) et de la Medicines and Healthcare Products Regulatory Agency (Royaume-Uni) ont été interrogées pour déterminer la disponibilité de formes pharmaceutiques orales adaptées aux enfants pour ces médicaments. Le statut réglementaire de chaque pays a également fait l'objet d'une comparaison. Pour les formes pharmaceutiques autorisées présentant des problèmes potentiels d'innocuité des excipients, les directives de l'AEM concernant le sorbitol, le propylène glycol, l'éthanol et le benzoate de sodium ont servi à déterminer si un usage pédiatrique était acceptable.

Résultats : Des 56 médicaments étudiés faisant l'objet d'une préparation magistrale, 27 (48\%) avaient une forme pharmaceutique commercialisée adaptée aux enfants en dehors du Canada. Au total, ces médicaments sont sur le marché canadien depuis une médiane de 35 ans et près de la moitié (27 [48 \%]) ont une indication pédiatrique au Canada.

Conclusions : Le Canada accuse un retard par rapport aux États-Unis et à l'Union européenne quant à la disponibilité et à l'accès à des formes pharmaceutiques adéquates pour les enfants. La petite taille du marché, les incertitudes en matière réglementaire et les lacunes concernant le remboursement pourraient notamment expliquer cet écart. II est nécessaire de prendre des mesures pour mettre en place des réglementations et des incitatifs ainsi que des politiques de remboursement axés sur les enfants pour répondre à ces besoins criants.

Mots-clés : préparation magistrale, médicaments adaptés aux enfants, médicaments pédiatriques pour administration orale 


\section{INTRODUCTION}

Every year, roughly half of Canada's 8 million children are given at least 1 prescription drug. The proportion is even higher among newborns and infants under the age of 1 year. ${ }^{1}$ Despite their widespread use for children of all ages, from premature newborns to adolescents, many medications given to children have no commercially available, age-appropriate formulations. This situation leads to numerous challenges, including the need for health care professionals and caregivers to manipulate dosage forms designed for adults, a process referred to as compounding. ${ }^{2,3}$ These manipulated medications fall outside of the Canadian regulatory approval process, and compounding results in "off-label" use of medications, with the efficacy and safety concerns that such use presents. ${ }^{1}$ Lack of appropriate drug formulations for children can lead to increased risk of errors and adverse events, lack of adherence because of taste issues, and suboptimal dosing with therapeutic failure. ${ }^{3-6}$ In addition, this practice uses time, money, and resources that could be directed to other aspects of pharmacy-related patient care if commercially available formulations were available.

Even though the practice of compounding is regulated by provincial pharmacy regulatory authorities and is essential to give young children access to medications, it should not be considered an equivalent surrogate for a pediatric formulation approved by Health Canada. Under the current requirements of Canada's Good Manufacturing Practices, compounded drugs are not overseen by Health Canada. Therefore, characteristics of compounded drugs are not as well established or controlled as those of approved formulations. This is particularly true with regard to stability, potency, content uniformity, purity, and bioavailability, among other characteristics. ${ }^{2,7}$ Most importantly, administration of the appropriate dose cannot be guaranteed because of the variations outlined above. ${ }^{8}$ Although every measure is taken to ensure that compounded drugs provide the most accurate dosing and are safe, errors do occur. ${ }^{9,10}$ These errors can result in lack of efficacy or, at worst, major side effects; in extreme cases, death may occur, as for an 8-year-old Canadian boy who died in 2016 after the compounding pharmacy that dispensed his sleep medication (tryptophan) accidentally switched it for another medication (baclofen). ${ }^{9}$

To address these challenges and ensure safe and effective drug use in Canadian children, the Goodman Pediatric Formulations Centre (GPFC) was created in February 2016 to facilitate the development of and access to pharmaceuticalgrade pediatric formulations.

As a first step toward this objective, the GPFC required a better understanding of the scope of the problem based on a patient-centric approach. The purpose of this study was to better define the unmet medical need for pediatric formulations in Canada by determining which drugs required compounding for oral administration in a Canadian tertiary pediatric hospital. For those compounded drugs, the availability and regulatory status of commercial pediatric oral formulations in the United States and/or the European Union were also determined.

\section{METHODS}

\section{Data Collection}

This retrospective study was conducted at the CHU SainteJustine, a Canadian university-affiliated tertiary pediatric hospital with 484 beds, in Montréal, Quebec. The hospital institutional review board deemed the study exempt from review.

The first step of the study was to identify drugs that required compounding for oral administration to children, which was accomplished using records in the $\mathrm{CHU}$ Sainte-Justine Pharmacy database. We included compounded oral liquid formulations dispensed from January 1 through December 31, 2015, and prepared in a quantity exceeding $0.5 \mathrm{~L}$ per year (a threshold chosen arbitrarily by the authors). Drugs for which splitting of an adult-formulation tablet was required were excluded because records for these drugs could not be retrieved from the Pharmacy database. Drugs compounded because of temporary back order during the study period were also excluded. The included drugs were subsequently classified according to the American Hospital Formulary Service Pharmacologic-Therapeutic Classification ${ }^{11}$ according to their specific therapeutic uses.

The second step of the study was to determine whether the oral compounded drugs were available as licensed oral pediatric formulations in the United States and/or the European Union. These regions were chosen because they are the most advanced in terms of pediatric regulations, and drug information is easily accessible. For each drug, the online drug databases of Health Canada, ${ }^{12}$ the US Food and Drug Administration (FDA), ${ }^{13}$ and the European Medicines Agency (EMA) ${ }^{14}$ were searched. For the European Union, if no commercialized pediatric formulations were identified in the EMA database, the UK Medicines and Healthcare Products Regulatory Agency (MHRA) database ${ }^{15}$ was searched. All databases were first searched on May 1, 2016. The Health Canada database was last accessed on February 28, 2019, whereas the other online databases were last accessed on September 30, 2018. From these website sources, product labels from all manufacturers were reviewed to extract the following data: the international nonproprietary name, the available dosage form(s), the strength (for capsules and tablets) or concentration (for oral liquid formulation) of the dosage form(s), the excipients, approved pediatric indications, and the approved lower age limit of the pediatric indication, if available. For Canada, the period since drug approval and patent status were also collected.

The medications were then classified into 4 categories on the basis of their commercial availability in the United States and/or the European Union, their pharmaceutical 
form, and the excipients used, as described on the product label (Table 1).

As the third step of the study, a simulation was conducted for drugs in category 3 (those available as commercial liquid form containing excipients with potential safety concerns) to determine whether the excipients with potential safety concerns exceeded the maximum daily threshold described in recently published EMA guidelines. These are currently the only regulatory excipient guidelines with pediatric thresholds: for sorbitol, $140 \mathrm{mg} / \mathrm{kg}$ daily for all age groups ${ }^{20}$; for propylene glycol, $1 \mathrm{mg} / \mathrm{kg}$ daily for children up to 1 month of age, $50 \mathrm{mg} / \mathrm{kg}$ daily for children between 1 month and 5 years of age, and $500 \mathrm{mg} / \mathrm{kg}$ daily for children older than 5 years $^{21}$; and for ethanol, $6 \mathrm{mg} / \mathrm{kg}$ daily for all age groups. ${ }^{22}$ For sodium benzoate, the EMA guidelines are limited to neonates, for whom use of this excipient is prohibited ${ }^{23}$; as such, any drug containing this excipient was declared unsuitable for this age group. The simulation process was based on the concentration of the excipient(s) (either provided on the product label or obtained directly from the manufacturer), the concentration of the drug, the usual maximum daily dose (as determined by clinical practice and endorsed by hospital pharmacists at the study institution), and children's weight by age (as per World Health Organization growth charts). ${ }^{24}$ When a liquid formulation was marketed by more than 1 manufacturer, the formulation with the lowest concentration of excipients was used for the simulation.

\section{Quality Control}

To ensure the quality and accuracy of the data, all data were extracted from the databases twice by different individuals (first extraction by 2 authors [A.C., D.G.] and 1 collaborator; second extraction by a third author [S.B.]). The authors discussed interpretation and classification issues during team meetings.

\section{Statistical Analyses}

Standard summary statistics, comprising percentages, medians, counts, and ranges to describe the study variables, were calculated using Excel for Mac, version 15.25.1 (160826) (Microsoft Corporation, Redmond, Washington). For the excipient exposure analysis, we first simulated a data set of children from birth to 12 years with weight distribution according to growth charts. ${ }^{24}$ We created a subset of this data set consisting of 3 simulated children per month of age, with the 3rd, 50th, or 97th percentile of weight for age, using R software $(n=435) .{ }^{25}$ For each oral formulation from category 3 , we estimated the excipient exposure according to the following equation, using Excel and the Power Pivot add-in (Excel 2016, Microsoft Corporation):

Excipient exposure (mg/day)

$$
=\frac{\text { Weight }(\mathrm{kg}) * \text { Dose }(\mathrm{mg} / \mathrm{kg} / \text { day }) * \text { Concentration }_{\mathrm{ex}}(\mathrm{mg} / \mathrm{mL})}{\text { Concentration }_{\text {drug }}(\mathrm{mg} / \mathrm{mL})}
$$

where Dose is the usual maximum daily dose (as determined in clinical practice and endorsed by hospital pharmacists at the study institution), Concentration $\mathrm{ex}_{\mathrm{ex}}$ is the concentration of the excipient in the oral formulation, and Concentration drug $_{\text {is }}$ the concentration of the drug in the oral formulation. The daily exposure ( $\mathrm{mg} /$ day) was further divided by weight $(\mathrm{kg})$. When the excipient component was expressed as $\mathrm{V} / \mathrm{V}$ (volume of excipient/volume of liquid drug) in the monograph, we converted to milligrams per millilitre (i.e., weight/volume of liquid) by multiplying by the specific gravity of each excipient. ${ }^{16}$

\section{RESULTS}

A total of 86 drugs were compounded as liquid preparations for oral administration in the study hospital over the 1 -year period. Thirty (35\%) of these drugs were excluded, either because the quantity prepared annually was $0.5 \mathrm{~L}$ or less $(n=24)$, the quantity prepared could not be retrieved from the database ( $n=1$ [ketamine]), or the preparation was considered an outlier ( $n=1$ [unusually large quantity of glycine prepared for several family members being treated for a rare hereditary condition]). In addition, 1 drug was compounded because of a temporary back order $(n=1$ [valganciclovir]), and 3 drugs were excluded because a pediatric

\begin{tabular}{|c|c|c|}
\hline Category & Definitions & $\begin{array}{l}\text { No. of Drugs } \\
\quad(n=56)\end{array}$ \\
\hline 1 & Available as commercial oral liquid with excipients known to be safe & 14 \\
\hline 2 & $\begin{array}{l}\text { Available as commercial nonliquid oral form, with ingredients known to be safe, such as chewable tablets and drugs } \\
\text { requiring manipulation by the caregiver before administration (e.g., powder or granules for oral suspension/solution, } \\
\text { scored tablets) }\end{array}$ & 5 \\
\hline 3 & $\begin{array}{l}\text { Available as commercial liquid form containing excipients with potential safety concerns, which could limit their use } \\
\text { in pediatrics, }{ }^{16,17} \text { such as ethanol, sodium benzoate, propylene glycol, and/or sorbitol (according to recently published } \\
\text { EMA guidelines on excipients }{ }^{18,19} \text { ) }\end{array}$ & 12 \\
\hline 4 & No commercial pediatric formulation approved by FDA, EMA, or MHRA & 25 \\
\hline
\end{tabular}

\section{TABLE 1. Commercial Availability Categories}

EMA = European Medicines Agency, FDA = Food and Drug Administration (US), MHRA = Medicines and Healthcare Products Regulatory Agency (UK). 
liquid formulation was approved and marketed in Canada (propranolol [Hemangiol], glycopyrrolate, and sevelamer) between the beginning and the end of the study.

As such, 56 drugs were included in the analysis, with annual volumes prepared ranging from 0.6 to $144 \mathrm{~L}$ (median $5.9 \mathrm{~L} /$ year). In most cases (50 [89\%]), the compounded liquid formulations were prepared using approved tablets or capsules. Of the remaining 6 drugs, the commercially available IV formulation was used for oral administration of 2 medications (midazolam and vancomycin), and oral liquid solutions were prepared using a pharmaceutical grade powder as the active ingredient for 4 medications (arginine, caffeine, sodium benzoate, and sodium phosphate dibasic). One of the drugs (cisapride) was no longer on the Canadian market in 2015, but was available (and had been obtained) through the Special Access Programme of Health Canada.

The 3 most frequent therapeutic areas for compounded drugs were cardiovascular $(n=17[30 \%])$, central nervous system $(n=11[20 \%])$, and anti-infective drugs ( $n=6[11 \%])$, and these accounted for $61 \%$ of all compounded liquid formulations. All 56 drugs were off-patent drugs and had been on the Canadian market for a median of 35 (range 14 to 65) years.

The distribution of the 56 drugs by category is shown in Table 1. Overall, 27 drugs (48\%) requiring compounding for administration to children were found to have suitable commercially available, child-friendly formulations outside of Canada: 14 (25\%) in category 1 (available as oral liquid with safe excipients; Table 2), 5 (9\%) in category 2 (available as nonliquid oral form with safe excipients; Table 3 ), and $8(14 \%)$ in category 3 (Table 4$)$. The annual quantity of these 27 compounded drugs ranged from 0.6 to $144 \mathrm{~L}$, with 9 (33\%) of them prepared in quantities exceeding $25 \mathrm{~L}$ (Figure 1). Eighteen of these drugs had a pediatric indication in their Canadian product monograph.

For drugs with safe excipients available in the United States and the European Union as oral liquids (category 1)

TABLE 2. Oral Liquid Formulations with Excipients Known to Be Safe for Children and Available in the United States or Europe but not in Canada (Category 1, $n=14$ )

\begin{tabular}{|c|c|c|c|c|c|c|c|c|}
\hline \multirow[b]{2}{*}{ Drug } & \multicolumn{2}{|c|}{ Canada (Health Canada) } & \multicolumn{3}{|c|}{ US (Food and Drug Administration) } & \multicolumn{3}{|c|}{ Europe* (MHRA) } \\
\hline & $\begin{array}{c}\text { Pediatric } \\
\text { Indication }^{\dagger}\end{array}$ & $\begin{array}{l}\text { Lower } \\
\text { Age Limit }\end{array}$ & $\begin{array}{c}\text { Pediatric } \\
\text { Indication }^{\dagger}\end{array}$ & $\begin{array}{l}\text { Lower } \\
\text { Age Limit }\end{array}$ & $\begin{array}{c}\text { Liquid } \\
\text { Concentration, } \\
\mathrm{mg} / \mathrm{mL}\left(\text { Form }^{\ddagger} \text { ) }\right.\end{array}$ & $\begin{array}{c}\text { Pediatric } \\
\text { Indication }^{\dagger}\end{array}$ & $\begin{array}{l}\text { Lower } \\
\text { Age Limit }\end{array}$ & $\begin{array}{c}\text { Liquid } \\
\text { Concentration, } \\
\mathrm{mg} / \mathrm{mL}\left(\text { Form }{ }^{\ddagger} \text { ) }\right.\end{array}$ \\
\hline Amitriptyline ${ }^{\S}$ & Yes & 12 years & Yes & 12 years & None & Yes & 6 years & $10 / 25 / 50$ (sol) \\
\hline Amlodipine ${ }^{\Uparrow}$ & Yes & 6 years & Yes & 6 years & None & Yes & 6 years & $1 / 2$ (sol) \\
\hline Enalapril & Yes & - & Yes & 1 month & 1 (sol) & Yes & - & None \\
\hline Folic acid ${ }^{\star * *}$ & Yes & 1 year & Yes & - & None & Yes & From birth & $1 / 2.5(\mathrm{sol})$ \\
\hline Levothyroxine & Yes & From birth & Yes & From birth & None & Yes & From birth & 0.05/0.1/0.2 (sol) \\
\hline Midazolam & Yes $^{\dagger \dagger}$ & - & Yes & 6 months & 2 (syr) & Yes & 3 months & $5(\mathrm{oms})^{\ddagger \ddagger}$ \\
\hline Nitrofurantoin & Yes & 1 month & Yes & 1 month & 5 (susp) & Yes & 3 months & 5 (susp) \\
\hline Phytonadione & Yes $^{\dagger t}$ & From birth & Yes $^{\dagger t}$ & From birth & None & Yes & From birth & $10(\mathrm{sol})^{\S \S}$ \\
\hline Rifampicin & Yes & - & Yes & - & None & Yes & 1 month & 20 (susp) \\
\hline Captopril & No & 18 years & No & 18 years & None & Yes & from birth & $1 / 5$ (sol) \\
\hline Gabapentin & No & 18 years & Yes & 3 years & 50 (sol) & Yes & 6 years & 50 (sol) \\
\hline Levetiracetam? & No & 18 years & Yes & 1 month & 100 (sol) & Yes & 1 month & 100 (sol) \\
\hline Sotalol & No & 18 years & Yes & - & 5 (sol) & No & 18 years & None \\
\hline Caffeine ${ }^{\| * *}$ & No & 18 years & Yes & From birth & 10/20 (sol) & Yes & From birth & 10/20 (sol) \\
\hline
\end{tabular}

Dash = not specified, "None" = liquid pediatric formulation unavailable.

*For all products, data were obtained from the UK Medicines and Healthcare Products Regulatory Agency (MHRA).

${ }^{\dagger}$ For oral administration, unless specified otherwise.

${ }^{\ddagger}$ Designations for pharmaceutical form: oms = oro-mucosal solution, sol = oral solution, susp = oral suspension, syr $=$ syrup.

$\S$ At least one formulation available with safe excipients.

"Amlodipine, levetiracetam, and caffeine oral solutions were not available in Canada at the time of study but have since been approved and commercialized in this country.

**Natural health product.

${ }^{+\dagger}$ Intravenous form only.

‡łPrefilled syringes for oral use containing $0.5,1,1.5$, or $2 \mathrm{~mL}$.

${ }_{\S}^{\S}$ Ampoules containing $2 \mathrm{mg}$ in $0.2 \mathrm{~mL}$, with oral dispensers provided in the pack. 
or oral nonliquids (category 2), the pharmaceutical forms and their approved pediatric indication are compared with the Canadian label in Tables 2 and 3, respectively. Among the category 2 drugs, both topiramate and lamotrigine are currently available in Canada (as 15- and 25-mg capsules for sprinkling and as 2- and 5-mg chewable/dispersible tablets, respectively); compounding of these drugs into an oral liquid formulation was done mainly because of the lack of dosing flexibility with the current strengths available in Canada. The higher strengths available in the United States and the European Union offer more dosing flexibility for these 2 drugs.

Among 12 drugs available in commercial liquid forms containing excipients with potential safety concerns (category 3), 8 were found (by the simulation described above) to be suitable for use in children (Table 4). Based on the usual maximum daily dose, 2 drugs were found to be suitable for all ages, 5 were suitable for children older than 1 month, and 1 was considered suitable with the limitation that it may cause undesirable gastrointestinal effects secondary to excess amounts of sorbitol. Of these 8 drugs, 5 were found to have a pediatric indication in Canada. The remaining 4 medications in category 3 were classified as either unsuitable, because of the presence of ethanol above the recommended threshold, or unknown, because of insufficient data from the manufacturer to draw conclusions about suitability.

In addition to the 4 drugs from category 3 that were classified as unsuitable or inconclusive, 25 medications (45\%) were found to have no commercialized pediatric oral formulations available in the United States or the European Union (EMA/MHRA) (category 4). The annual quantity of these compounded drugs ranged from 0.8 to $105 \mathrm{~L}$, with $6(21 \%)$ of them prepared in quantities of $25 \mathrm{~L}$ or more (Figure 2).
Nine of these drugs had a pediatric indication in their Canadian product monographs.

\section{DISCUSSION}

This study represents the first step toward improving the availability of and access to age-appropriate drug formulations for Canadian children, because it provides pivotal information regarding the unmet need for pediatric formulations. We identified 56 drugs that were frequently compounded as oral liquid formulations and showed that for almost half of these drugs (48\%), child-friendly oral formulations are commercially available in the United States and/or the European Union. It is difficult to explain why in a developed G7 country such as Canada, compounding of drugs that have been on the Canadian market for a median of 35 years is a standard of care for children, especially when these medications are available as suitable pediatric formulations elsewhere.

One striking example of how Canada is lagging behind other countries is the case of levetiracetam, a secondgeneration anti-epileptic drug that is widely used to manage partial seizures in children and adults. ${ }^{26}$ In 2003, levetiracetam was approved in Canada for adults (18 years of age or older) with epilepsy, without mention of a pediatric indication or availability of a pediatric formulation. ${ }^{27}$ It was only recently, in July 2019, that a pediatric indication was added to the Canadian product monograph, with approval of an oral solution, which is now (as of May 2020) commercialized in Canada. This situation contrasts with that in the United States and the European Union, where a pediatric indication for levetiracetam was granted in 2005 , along with approval

TABLE 3. Oral Nonliquid Formulations with Excipients Known To Be Safe for Children and Available in the United States or Europe (Category $2, n=5$ )

\begin{tabular}{|c|c|c|c|c|c|c|c|c|c|}
\hline \multirow[b]{2}{*}{ Drug } & \multicolumn{3}{|c|}{$\begin{array}{c}\text { Canada } \\
\text { (Health Canada) }\end{array}$} & \multicolumn{3}{|c|}{$\begin{array}{c}\text { United States } \\
\text { (Food and Drug Administration) }\end{array}$} & \multicolumn{3}{|c|}{$\begin{array}{c}\text { Europe* } \\
\text { (EMA/MHRA) }\end{array}$} \\
\hline & $\begin{array}{l}\text { Pediatric } \\
\text { Indication }\end{array}$ & $\begin{array}{l}\text { Lower Age } \\
\text { Limit } \\
\text { (years) }\end{array}$ & $\begin{array}{c}\text { Dosage } \\
\text { Strength, } \\
\left.\text { mg (Form }{ }^{\dagger}\right)\end{array}$ & $\begin{array}{l}\text { Pediatric } \\
\text { Indication }\end{array}$ & $\begin{array}{l}\text { Lower Age } \\
\text { Limit } \\
\text { (years) }\end{array}$ & $\begin{array}{c}\text { Dosage } \\
\text { Strength, } \\
\mathrm{mg}\left(\text { Form }^{\dagger}\right)\end{array}$ & $\begin{array}{l}\text { Pediatric } \\
\text { Indication }\end{array}$ & $\begin{array}{l}\text { Lower Age } \\
\text { Limit } \\
\text { (years) }\end{array}$ & $\begin{array}{c}\text { Dosage } \\
\text { Strength, } \\
\left.\text { mg (Form }{ }^{\dagger}\right)\end{array}$ \\
\hline Hydrocortisone & Yes & - & None & Yes & - & None & Yes & 0 & $0.5 / 1 / 2 / 5$ (gсo) \\
\hline Tacrolimus & Yes & - & None & Yes & - & $0.2 / 1$ (gs) & Yes & - & $0.2 / 1$ (gs) \\
\hline Topiramate & Yes & 2 & $15 / 25(\mathrm{cs})^{\ddagger}$ & Yes & 2 & $15 / 25$ (cs) & Yes & 2 & $15 / 25 / 50$ (cs) \\
\hline Lamotrigine & Yes & - & $2 / 5(\mathrm{cdt})^{\ddagger}$ & Yes & 2 & $2 / 5 / 25(\mathrm{cdt})$ & Yes & 2 & $2 / 5 / 25 / 100(\mathrm{cdt})$ \\
\hline Hydroxyurea & no & 18 & None & Yes & 2 & $100 / 1000(s t)$ & Yes & 2 & $100 / 1000$ (st) \\
\hline
\end{tabular}

Dash $=$ not specified, EMA = European Medicines Agency, MHRA = UK Medicines and Healthcare Products Regulatory Agency, "None" = nonliquid pediatric formulation unavailable.

*Data for tacrolimus, topiramate, and lamotrigine were obtained from the MHRA; data for hydrocortisone and hydroxyurea were obtained from the EMA. ${ }^{\dagger}$ Designations for pharmaceutical form: $c d t=$ chewable dispersible tablet, $c s=$ capsule to sprinkle, gco = granules in capsule for opening, $g s=g r a n u l e s$ for suspension, st $=$ scored tablet.

${ }^{\ddagger}$ Despite the availability of pediatric-friendly dosage forms in Canada, the strengths available are not sufficient to cover pediatric dosage needs; therefore, these 2 formulations are considered suboptimal in Canada. 
TABLE 4. Suitability of Oral Liquid Formulations with Potentially Harmful Excipients for Children Available in the United States or Europe (Category 3, $n=12$ )

\begin{tabular}{|c|c|c|c|}
\hline Drug (Region*) & $\begin{array}{l}\text { Potentially } \\
\text { Harmful Excipient }\end{array}$ & $\begin{array}{l}\text { Age Group for Which Toxic } \\
\text { Threshold }^{\dagger} \text { Is Reached or Exceeded }\end{array}$ & Suitability for Children \\
\hline $\begin{array}{l}\text { Baclofen }^{\ddagger} \\
5 \mathrm{mg} / 5 \mathrm{~mL}(\mathrm{UK})\end{array}$ & Propylene glycol & $\begin{array}{l}\leq 1 \text { month } \\
\text { Baclofen is not given to neonates; } \\
\text { therefore, no simulation was done } \\
\text { for this age group }\end{array}$ & $\begin{array}{l}\text { Suitable for children }>1 \text { month of age at a usual } \\
\text { maximum dose of } 20 \mathrm{mg} / \text { day for children }>1 \text { month to } \\
2 \text { years of age or } 40 \mathrm{mg} / \text { day for children }>2 \text { years of age }\end{array}$ \\
\hline $\begin{array}{l}\text { Dexamethasone }^{\ddagger} \\
10 \mathrm{mg} / 5 \mathrm{~mL} \\
20 \mathrm{mg} / 5 \mathrm{~mL} \\
\text { (UK) }\end{array}$ & Propylene glycol & $\leq 1$ month & $\begin{array}{l}\text { Suitable for children }>1 \text { month of age at a usual } \\
\text { maximum dose of } 1 \mathrm{mg} / \mathrm{kg} \text { daily }\end{array}$ \\
\hline $\begin{array}{l}\text { Domperidone } \\
1 \mathrm{mg} / \mathrm{mL} \text { (UK) }\end{array}$ & Sorbitol & All ages & $\begin{array}{l}\text { May cause GI discomfort and mild laxative effects at usual } \\
\text { maximum doses of } 0.75 \mathrm{mg} / \mathrm{kg} \text { daily for children } \leq 1 \text { month } \\
\text { of age and } 2.4 \mathrm{mg} / \mathrm{kg} \text { daily for children }>1 \text { month old }\end{array}$ \\
\hline $\begin{array}{l}\operatorname{Losartan}^{\ddagger} \\
2.5 \mathrm{mg} / \mathrm{mL} \text { (EU) }\end{array}$ & Sorbitol & None & $\begin{array}{l}\text { Suitable for children of all ages at usual maximum } \\
\text { dose of } 1.4 \mathrm{mg} / \mathrm{kg} \text { daily }\end{array}$ \\
\hline \multirow[t]{2}{*}{$\begin{array}{l}\text { Metronidazole }{ }^{\ddagger} \\
200 \mathrm{mg} / 5 \mathrm{~mL} \text { (UK) }\end{array}$} & Sorbitol & None & $\begin{array}{l}\text { Suitable for children }>1 \text { month of age at a usual } \\
\text { maximum dose of } 30 \mathrm{mg} / \mathrm{kg} \text { daily }\end{array}$ \\
\hline & Propylene glycol & $\leq 1$ month & \\
\hline $\begin{array}{l}\text { Sildenafi|\$q } \\
10 \mathrm{mg} / \mathrm{mL}(\mathrm{EU})\end{array}$ & Sorbitol & None & $\begin{array}{l}\text { Suitable for children of all ages at the usual maximum } \\
\text { dose of } 4.0 \mathrm{mg} / \mathrm{kg} \text { daily; may cause } \mathrm{Gl} \text { discomfort and mild } \\
\text { laxative effects if used at doses }>5.6 \mathrm{mg} / \mathrm{kg} \text { daily }\end{array}$ \\
\hline $\begin{array}{l}\text { Ursodiol}^{\S} \\
50 \mathrm{mg} / \mathrm{mL} \\
\text { (UK) }\end{array}$ & Sodium benzoate & No simulation conducted & $\begin{array}{l}\text { Suitable for children }>1 \text { month of age at a maximum } \\
\text { dose of } 30 \mathrm{mg} / \mathrm{kg} \text { daily; product is contraindicated for } \\
\text { neonates because of the presence of sodium benzoate, } \\
\text { which may cause neonatal jaundice }\end{array}$ \\
\hline $\begin{array}{l}\text { Vancomycin } \\
25 \text { and } 50 \mathrm{mg} / \mathrm{mL} \\
\text { (US) }\end{array}$ & Sodium benzoate & No simulation conducted & $\begin{array}{l}\text { Suitable for children }>1 \text { month of age; product is } \\
\text { contraindicated for neonates because it contains sodium } \\
\text { benzoate, which may cause neonatal jaundice }\end{array}$ \\
\hline $\begin{array}{l}\text { Diazoxide }^{\ddagger} \\
50 \mathrm{mg} / \mathrm{mL} \text { (US) }\end{array}$ & Ethanol & All ages & $\begin{array}{l}\text { Not suitable for children at any age at a maximum } \\
\text { dose of } 10 \mathrm{mg} / \mathrm{kg} \text { daily for children }<1 \text { month of age, } \\
15 \mathrm{mg} / \mathrm{kg} \text { daily for children from } 1 \text { month to } 1 \text { year of age, } \\
\text { and } 8 \mathrm{mg} / \mathrm{kg} \text { daily for children older than } 1 \text { year }\end{array}$ \\
\hline $\begin{array}{l}\text { Prednisone }{ }^{\ddagger} \\
1 \text { and } 5 \mathrm{mg} / \mathrm{mL} \text { (US) }\end{array}$ & Ethanol & All ages & $\begin{array}{l}\text { Not suitable for children at any age at a maximum dose } \\
\text { of } 2 \mathrm{mg} / \mathrm{kg} \text { daily }\end{array}$ \\
\hline $\begin{array}{l}\text { Levofloxacin } \\
25 \mathrm{mg} / \mathrm{mL} \text { (US) }\end{array}$ & Propylene glycol & $\begin{array}{l}\text { No simulation conducted; } \\
\text { amount of excipient not reported } \\
\text { by the manufacturer }\end{array}$ & Unable to draw conclusions \\
\hline $\begin{array}{l}\text { Lorazepam }^{\S} \\
2 \mathrm{mg} / \mathrm{mL} \text { (US) }\end{array}$ & Propylene glycol & $\begin{array}{l}\text { No simulation conducted; } \\
\text { amount of excipient not reported } \\
\text { by the manufacturer }\end{array}$ & Unable to draw conclusions \\
\hline
\end{tabular}

EMA = European Medicines Agency, FDA = Food and Drug Administration (US), GI = gastrointestinal, MHRA = Medicines and Healthcare Products Regulatory Agency (UK).

*For designations of region, EU = drugs approved by the EMA, UK = drugs approved by the MHRA, and US = drugs approved by the FDA.

${ }^{\dagger}$ Thresholds as per EMA guidance: for sorbitol, $140 \mathrm{mg} / \mathrm{kg}$ daily for all age groups ${ }^{20}$; for propylene glycol, $1 \mathrm{mg} / \mathrm{kg}$ daily for children up to $1 \mathrm{month}$ of age, $50 \mathrm{mg} / \mathrm{kg}$ daily for children 1 month to 5 years of age, and $500 \mathrm{mg} / \mathrm{kg}$ daily for children older than 5 years ${ }^{21}$; for ethanol, $6 \mathrm{mg} / \mathrm{kg}$ daily for all age groups ${ }^{22}$; for sodium benzoate, the threshold is 0 for neonates (children under 1 month of age) only, ${ }^{23}$ so any drug containing this excipient is declared unsuitable for this age group.

‡Solid oral dosage form approved for pediatric use in Canada.

§olid oral dosage form not approved for pediatric use in Canada.

"Powder reconstituted at the pharmacy. 


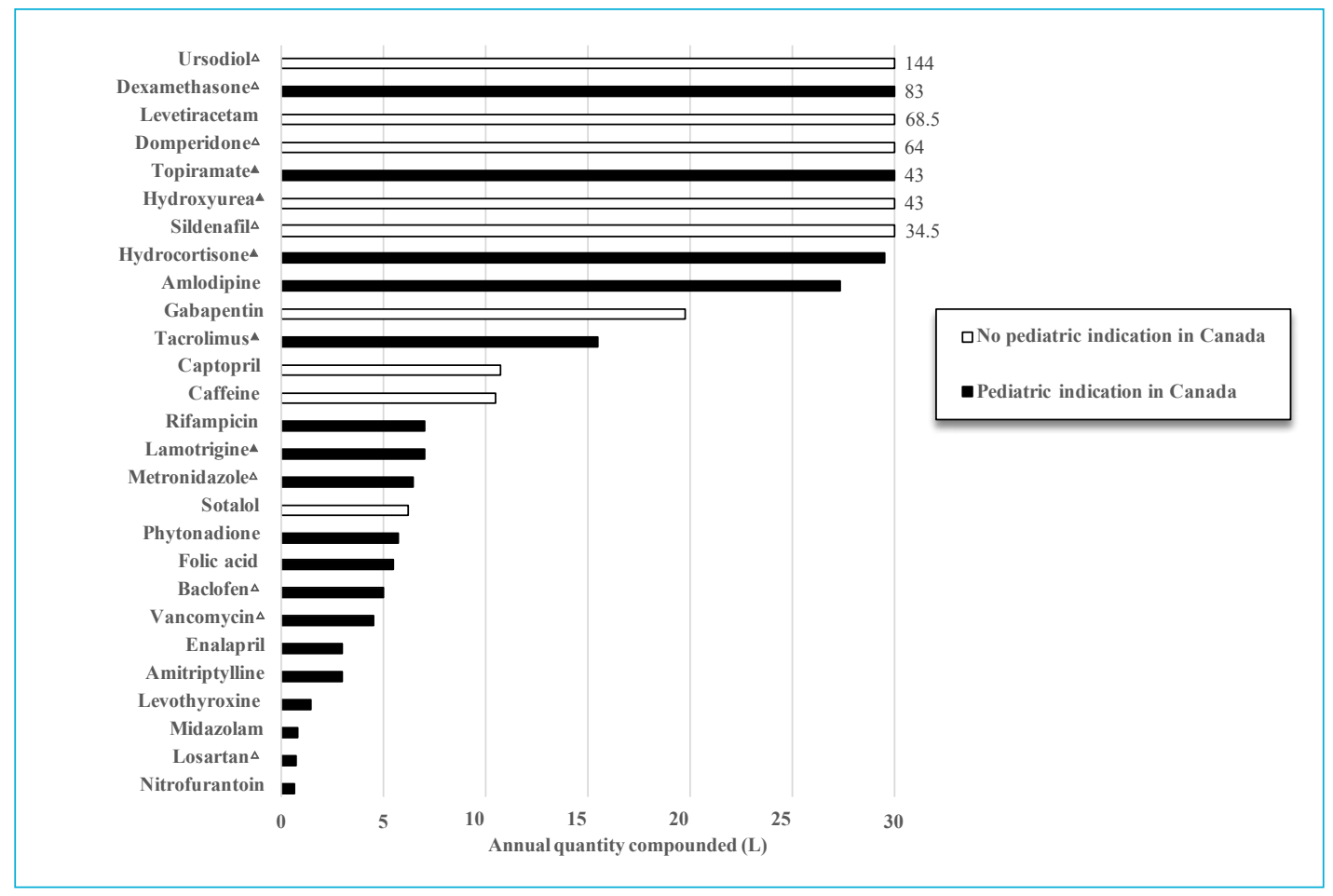

FIGURE 1. Annual quantity (L) and regulatory status of drugs compounded at a tertiary pediatric hospital for which commercial formulations suitable for children are available in the United States or the European Union (EMA/MHRA). Solid triangle = nonliquid oral form (category 2); open triangle = liquid oral form containing an excipient with potential safety concern (category 3). Levetiracetam and caffeine were not indicated for children at the time of database searching but are now indicated for pediatric use in Canada.

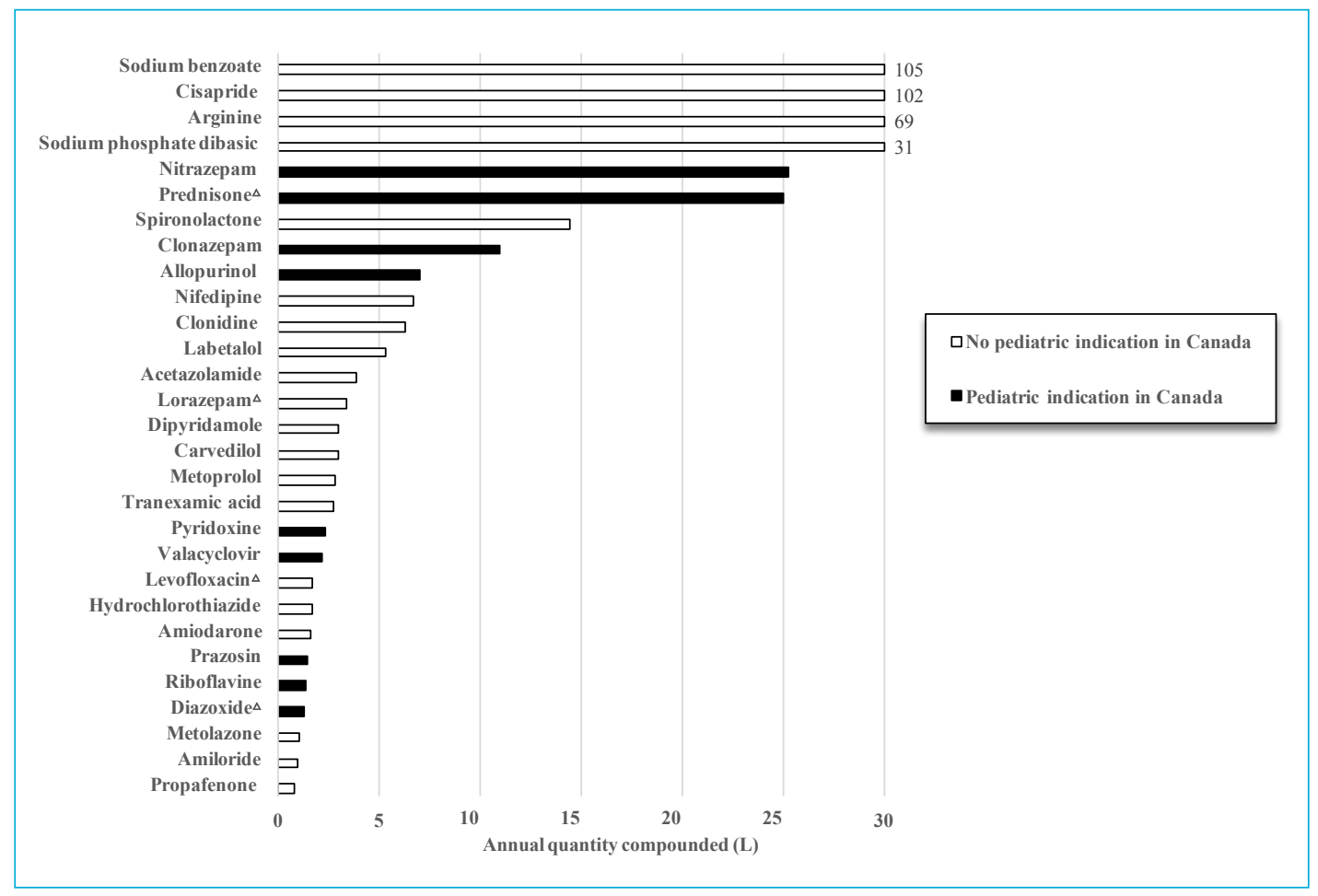

FIGURE 2. Annual quantity $(\mathrm{L})$ and regulatory status of drugs compounded at a tertiary pediatric hospital for which no commercial formulation suitable for use in children is available in the United States or the European Union (EMA/MHRA). Open triangle $=$ liquid oral form containing an excipient with potential safety concern (category 3 ). 
of a child-friendly formulation. ${ }^{28,29}$ This represents close to 15 years of delay for Canada, a situation that calls for action.

Our findings should prompt all stakeholders to ask why pediatric formulations are not being commercialized in Canada. We suspect that major reasons may include small market size (with Canada representing at most $2 \%$ of the global market), ${ }^{30}$ along with regulatory uncertainties and reimbursement shortcomings. Compared with the United States and Europe, Canada falls behind in regulatory provisions related to pediatric drug development. Unlike Health Canada, the FDA and EMA have implemented specific regulations, through a system of requirements and incentives, to drive the development of appropriately licensed and formulated drugs for children, both patented and off-patent. With these systems in place, manufacturers are obliged to assess the safety and effectiveness of new drugs and biologics in pediatric patients if there is anticipated use in children, and incentives such as patent extensions may be provided to give manufacturers additional market exclusivity. These pediatric-specific regulations have translated into significant progress, ${ }^{31}$ and Canada should build on these experiences.

Currently, Canada has no specific regulations for submission of pediatric formulations already approved in other countries. Recently, Health Canada has been evaluating a pathway for using foreign reviews and decisions to facilitate Canadian access to drugs, which was expected to come into effect in spring 2020, ${ }^{32}$ but as of summer 2020 had not been endorsed. External consultations held in 2017 and 2018 indicated that this pathway will have reduced review timelines and fees, relative to the usual approval pathway. The 27 drugs identified in this study for which pediatric formulations are available in the United States and/or Europe would be ideal candidates to benefit from this initiative. However, we are concerned that the intent to require substantial international postmarket experience (i.e., 15 years) in other jurisdictions will constitute a major barrier, as it may disqualify many child-friendly medications.

Furthermore, under current policies, submissions for pediatric formulations do not meet the criteria for priority review. However, this situation may change in the near future, given Health Canada's release, at the end of May 2019, of the document Draft Guidance: Accelerated Review of Human Drug Submissions. ${ }^{33}$ This accelerated review policy will encompass both the Priority Review of Drug Submissions policy and the Notice of Compliance with Conditions policy. It will thus provide an overarching policy by which critical drugs can be reviewed on an accelerated basis. The document specifically states that pediatric formulations could qualify for such accelerated review.

Once a drug is approved by Health Canada, significant barriers involving reimbursement and pricing may impede access to pediatric formulations. Depending on the medication type and its patent status, review by means of health technology assessment processes (through the Institut national d'excellence en santé et en services sociaux in Quebec and through the Canadian Agency for Drugs and Technologies in Health for the rest of Canada) may be needed. After the health technology assessment is complete, the drug must then be reviewed by the Patented Medicine Prices Review Board (if still on patent) and/or the Pan-Canadian Pharmaceutical Alliance (for both patented and generic medicines). Finally, the public drug plan in each province evaluates whether it will list, and therefore pay for, the new drug, on the basis of a budget comparison against the established cost of current treatment. ${ }^{26}$ Many of these evaluation processes are built on criteria applicable to adult forms, which may not apply, or may not be possible, in children. Hence, reimbursement for a pediatric formulation may be rejected. A recent example of this unfortunate situation occurred with Hemangiol, a pediatric propranolol solution approved by Health Canada and reimbursed in over 20 countries for the treatment of infantile hemangioma. Neither of the Canadian health technology assessment agencies supported its reimbursement because they used, for purposes of their budget impact analysis, the cost of the compounded propranolol formulation (which is relatively inexpensive) and therefore evaluated Hemangiol as being too expensive. It is impossible for a medication that has been manufactured in a highly controlled environment in accordance with Good Manufacturing Practices, and for which pediatric studies (with their associated costs) have been performed, to be comparable in price to a compounded preparation of the same drug, especially when the drug of interest is old and inexpensive. After further negotiation between the parties involved, Hemangiol is now reimbursed and available to Canadian children (Islam Mahmoud, Pierre Fabre Laboratories; personal communication, July 15, 2020) but some challenges, which are beyond the scope of this article, still remain for health care providers and for patients and their families. This case reinforces the need for alignment between regulatory and reimbursement processes, as well as the need to develop pediatric-specific criteria for drug evaluation by health technology assessment bodies, with recognition of the added safety and efficacy of a commercial pediatric formulation over a compounded preparation.

To encourage commercialization of off-patent drugs for children, the EMA instituted, as part of the European Union's 2007 pediatric legislation, the Paediatric Use Market Authorisation program, which offers 10 years of data exclusivity for the development and commercialization of pediatric formulations of older drugs. ${ }^{34}$ Ten years after implementation of the legislation, this program has not been as successful as anticipated. One potential explanation for this outcome is the lack of alignment between regulatory and reimbursement systems, given that reimbursement processes are country-specific.

We also identified 29 frequently compounded drugs for which no suitable pediatric formulation was marketed in the United States or the European Union (EMA/MHRA). A 
classic example is clonidine, which has been on the Canadian market for over 40 years and is still used as an off-label compounded formulation for children of all ages, for multiple conditions such as hypertension, neonatal abstinence syndrome, agitation and pain in the pediatric intensive care unit, and attention deficit/hyperactivity disorder, to name just a few. To address this gap, the development of innovative dosage forms, such as mini-tablets, in addition to liquid forms, should be considered. We truly hope that in the near future, with all of the available technologies, international multidisciplinary collaborations involving regulators, reimbursement bodies, industry, and other major stakeholders will result in the successful development of pediatric formulations of old drugs.

Our study had some limitations. It focused on frequently compounded drugs in a university-affiliated tertiary pediatric hospital, which may not accurately reflect the compounding reality of community hospitals or the outpatient setting (although many of the included drugs are often used outside the hospital). Because only medications compounded as oral liquid formulations were studied, some commonly compounded medications that undergo tablet splitting were not included; as such, our results likely underestimate the need for pediatric formulations. Furthermore, this study does not provide information about compounding of drugs that are administered parenterally (i.e., by IV, intramuscular, topical, and other routes). We considered the regulatory status and availability of these compounded medications only in the United States and the European Union (with information on drug status and availability coming mainly from the MHRA database); thus, we may have missed suitable pediatric formulations marketed in other jurisdictions. Finally, because the approval of drugs is an ongoing process, the situation for some drugs may have changed between the time the databases were last accessed and the time of publication. This has already occurred for amlodipine, levetiracetam, and caffeine oral solutions, which were not available as pediatric formulations at the time of database searching but are now (summer 2020) approved and commercialized in Canada for pediatric use.

\section{CONCLUSION}

What emerges from this study is that Canada is clearly lagging behind the United States and Europe in ensuring availability of and access to suitable pediatric formulations in a timely manner. Children account for almost one-fifth of the Canadian population, and they deserve the same standards as adults in terms of pharmaceutical forms designed to suit their needs, so as to maximize drug efficacy and safety. Steps must be taken to implement pediatric-sensitive regulations and incentives, as well as reimbursement policies, to fill this important gap. Furthermore, collaboration among all stakeholders is urgently needed to better understand the obstacles and hurdles from everyone's perspective, with the ultimate goal of defining for Canada a new sustainable model that will address the unmet needs for pediatric formulations of old off-patent drugs, as well as new drugs.

\section{References}

1. Expert Panel on Therapeutic Products for Infants, Children, and Youth. Improving medicines for children in Canada. Council of Canadian Academies; 2014 [cited 2019 Nov 25]. Available from: https://ccareports.ca/wp-content/uploads/2018/10/therapeutics_fullreporten.pdf

2. Zajicek A, Fossler MJ, Barrett JS, Worthington JH, Ternik R, Charkoftaki G, et al. A report from the Pediatric Formulations Task Force: perspectives on the state of child-friendly oral dosage forms. AAPS J. 2013;15(4):1072-81.

3. Ivanovska V, Rademaker CM, van Dijk L, Mantel-Teeuwisse AK Pediatric drug formulations: a review of challenges and progress. Pediatrics. 2014;134(2):361-72.

4. Parrish RH. Current trends and emerging priorities in compounded preparations for children. Int J Pharm Compound. 2018;22(5):358-66.

5. Nunn T, Williams J. Formulations of medicines for children. Br J Clin Pharmacol. 2005;59(6):674-6.

6. Rood JM, Engels MJ, Ciarkowski SL, Wagenknecht LD, Dickinson CJ, Stevenson JG. Variability in compounding of oral liquids for pediatric patients. J Am Pharm Assoc (2003). 2014;54(4):383-9.

7. Haywood A, Glass BD. Liquid dosage forms extemporaneously prepared from commercially available products - considering new evidence on stability. J Pharm Sci. 2013;16(3):441-55.

8. Richey RH, Shah UU, Peak M, Craig JV, Ford JL, Barker CE, et al Manipulation of drugs to achieve the required dose is intrinsic to paediatric practice but is not supported by guidelines or evidence. BMC Pediatr. 2013;13:Article 81.

9. Death due to pharmacy compounding error reinforces need for safety focus. ISMP Can Saf Bull. 2017;17(5):1-5.

10. Conroy $\mathrm{S}$. Association between licence status and medication errors. Arch Dis Child. 2011;96(3):305-6.

11. AHFS pharmacologic-therapeutic classification [database online]. American Society of Health-System Pharmacists; [cited 2017 Sep 9 ]. Available from: www.ahfsdruginformation.com/ahfs-pharmacologictherapeutic-classification/

12. Drug product database: access the database [database online]. Health Canada; [cited 2019 Feb 28]. Available from: https://www.canada.ca/ en/health-canada/services/drugs-health-products/drug-products/ drug-product-database.html

13. Drugs@FDA: FDA-approved drugs [database online]. Food and Drug Administration (US); [cited 2018 Sep 30]. Available from: https:// www.accessdata.fda.gov/scripts/cder/daf/index.cfm

14. Medicines [database online]. European Medicines Agency; (C) 1995-2020 [cited 2018 Sep 30]. Available from: https://www.ema.europa.eu/en/ medicines/field ema_web_categories\%253Aname field/Human

15. Guidance: find product information about medicines. Medicines and Healthcare Products Regulatory Agency (UK); 2018 [cited 2018 Sep 30]. Available from: www.mhra.gov.uk./spc-pil/

16. Arthur S, Burgess A. How to identify and manage 'problem' excipients in medicines for children. Pharm J. 2017;299(7903):42-5.

17. Walsh J, Cram A, Woertz K, Breitkreutz J, Winzenburg G, Turner R, et al. Playing hide and seek with poorly tasting paediatric medicines: do not forget the excipients. Adv Drug Deliv Rev. 2014;73:14-33.

18. Volume 2C: Guidelines. Medicinal products for human use. Safety, environment and information. Excipients in the labelling and package leaflet of medicinal products for human use. European Medicines Agency; 2018 Mar [cited 2018 May 15]. Available from: https://ec. europa.eu/health/sites/health/files/files/eudralex/vol-2/c/guidelines excipients_march2018_en.pdf

19. Annex to the European Commission guideline on 'Excipients in the labelling and package leaflet of medicinal products for human use' (SANTE-2017-11668). EMA/CHMP/302620/2017 Rev 1. European 
Medicines Agency; 2019 Nov 22 [cited 2019 Dec 8]. Available from: https://www.ema.europa.eu/documents/scientific-guideline/annexeuropean-commission-guideline-excipients-labelling-packageleaflet-medicinal-products-human_en.pdf

20. Committee for Human Medicinal Products. Information for the packageleaflet regarding fructose and sorbitol used as excipientsin medicinal products for human use. EMA/CHMP/460886/2014. European Medicines Agency; 2017 Oct 9 [cited 2018 May 15]. Available from: https:// www.ema.europa.eu/documents/scientific-guideline/informationpackage-leaflet-regarding-fructose-sorbitol-used-excipients-medicinalproducts-human-use_en.pdf

21. Committee for Human Medicinal Products. Propylene glycol used as an excipient. Report published in support of the 'Questions and answers on propylene glycol used as an excipient in medicinal products for human use'. EMA/CHMP/334655/2013. European Medicines Agency; 2017 Oct [cited 2018 May 15]. Available from: https://www. ema.europa.eu/documents/report/propylene-glycol-used-excipientreport-published-support-questions-answers-propylene-glycol-used _en.pdf

22. Committee for Human Medicinal Products. Questions and answers on ethanol in the context of the revision of the guideline on 'Excipients in the label and package leaflet of medicinal products for human use' (CPMP/463/00) [draft]. EMA/CHMP/507988/2013. European Medicines Agency; 2014 Jan 23 [cited 2018 May 15]. Available from: https://www.ema.europa.eu/documents/scientific-guideline/questionsanswers-ethanol-context-revision-guideline-excipients-label-packageleaflet-medicinal_en.pdf

23. Committee for Human Medicinal Products. Questions and answers on benzoic acid and benzoates used as excipients in medicinal products for human use. EMA/CHMP/508189/2013. European Medicines Agency; 2017 Oct 9 [cited 2018 May 15]. Available from: https://www. ema.europa.eu/documents/scientific-guideline/questions-answersbenzoic-acid-benzoates-used-excipients-medicinal-products-humanuse_en.pdf

24. Dieticians of Canada, Canadian Paediatric Society, College of Family Physicians of Canada, Community Health Nurses of Canada. Promoting optimal monitoring of child growth in Canada: using the new WHO growth charts. Can J Dietetic Pract Res. 2010;71(1):e1-e3.

25. R Core Team. $R$ : a language and environment for statistical computing. R Foundation for Statistical Computing; 2018 [cited 2019 Aug 20]. Available from: https://www.R-project.org/

26. Ndegwa S. Levetiracetam for the treatment of epilepsy [Environmental Scan issue 30]. Canadian Agency for Drugs and Technologies in Health; 2011 [cited 2019 Jul 15]. Available from: https://www.cadth. ca/sites/default/files/pdf/Keppara_Epilepsy_es-30.pdf

27. Keppra levetiracetam tablets of $250 \mathrm{mg}, 500 \mathrm{mg}$, and $750 \mathrm{mg}$. Antiepileptic agent [product monograph]. UCB Canada Inc; revised 2018 Sep [cited 2020 Jul 22]. Available from: https://www.ucb-canada.ca/_up/ ucbpharma_ca_en/documents/Keppra-pm-en-20sept2018.pdf

28. Keppra (levetiracetam) tablets, for oral use. Keppra (levetiracetam) oral solution [US prescribing information]. UCB Inc; revised 2019 Oct [cited 2020 Jul 22]. Available from: https://www.ucb.com/_up/ucb_ com_products/documents/Keppra_IR_Current_COL_10_2019.pdf

29. Keppra $100 \mathrm{mg} / \mathrm{ml}$ oral solution [EU summary of product characteristics]. UCB Pharma Limited; revised 2020 Jan [cited 2020 Jul 22]. Available from: https://www.medicines.org.uk/emc/product/2295/smpc

30. Canada's pharmaceutical industry and prospects. Industry Canada; 2013 [cited 2019 May 23]. Available from: https://www.ic.gc.ca/ eic/site/lsg-pdsv.nsf/vwapj/PharmaProfileFeb2014_Eng.pdf/\$file/ PharmaProfileFeb2014_Eng.pdf

31. Yen E, Davies JM, Milne CP. Impact of regulatory incentive programs on the future of pediatric drug development. Ther Innov Regul Sci. 2019;53(5):609-14.

32. Use of foreign reviews and decisions. Health Canada; 2019 Jul 17 [cited 2019 May 23]. Available from:https://www.canada.ca/en/health-canada/ corporate/transparency/regulatory-transparency-and-openness/ improving-review-drugs-devices/use-of-foreign-reviews-anddecisions.html

33. Consultation on draft guidance: accelerated review of human drug submissions. Health Canada; 2019 [cited 2019 Jun 18]. Available from: https://www.canada.ca/en/health-canada/programs/consultationdraft-guidance-accelerated-review-human-drug-submissions.html

34. State of paediatric medicines in the EU: 10 years of the EU Paediatric Regulation [COM (2017) 626]. Commission to the European Parliament and the Council; 2017 [cited 2019 Jun 18]. Available from: https://ec.europa.eu/health/sites/health/files/files/paediatrics/ docs/2017_childrensmedicines_report_en.pdf

Catherine Litalien, MD, FRCPC, is with the Rosalind \& Morris Goodman Family Pediatric Formulations Centre, the Department of Medical Biology, and the Research Centre of the CHU Sainte-Justine, Montréal, Quebec. She is also with the Department of Pediatrics and the Department of Pharmacology and Physiology, Université de Montréal, Montréal, Quebec

Julie Autmizguine, MD, FRCPC, MSc, is with the Rosalind \& Morris Goodman Family Pediatric Formulations Centre, the Department of Medical Biology, and the Research Centre of the CHU Sainte-Justine, Montréal, Quebec. She is also with the Department of Pediatrics and the Department of Pharmacology and Physiology, Université de Montréal, Montréal, Quebec.

Antoine Carli, BPharm, MSc, is with the Rosalind \& Morris Goodman Family Pediatric Formulations Centre of the CHU Sainte-Justine, Montréal, Quebec.

Denis Giroux, BPharm, MSc, is with the Rosalind \& Morris Goodman Family Pediatric Formulations Centre of the CHU Sainte-Justine, Montréal, Quebec.

Denis Lebel, BPharm, MSc, FCSHP, is with the Rosalind \& Morris Goodman Family Pediatric Formulations Centre and the Department of Pharmacy, CHU Sainte-Justine, Montréal, Quebec.

Jean-Marie Leclerc, MD, FRCPC, is with the Rosalind \& Morris Goodman Family Pediatric Formulations Centre and the Department of Medical Biology of the CHU Sainte-Justine, Montréal, Quebec. He is also with the Department of Pediatrics, Université de Montréal, Montréal, Quebec.

Yves Théorêt, BPharm, PhD, is with the Rosalind \& Morris Goodman Family Pediatric Formulations Centre, the Department of Medical Biology, and the Research Centre of the CHU Sainte-Justine, Montréal, Quebec. He is also with the Department of Pharmacology and Physiology, Université de Montréal, Montréal, Quebec.

Andrea Gilpin, PhD, is with the Rosalind \& Morris Goodman Family Pediatric Formulations Centre of the CHU Sainte-Justine, Montréal, Quebec.

Sophie Bérubé, BPharm, MSc, is with the Rosalind \& Morris Goodman Family Pediatric Formulations Centre of the CHU Sainte-Justine, Montréal, Quebec.

Competing interests: For activities outside the scope of the work reported here, Julie Autmizguine has received contract funding from Pharmascience and consulting fees from Astellas Pharma; Jean-Marie Leclerc has received contract funding from Rare Disease Therapeutics (US); Yves Théorêt has received contract funding from Rare Disease Therapeutics (US) and Leon NanoDrugs (Germany); and Catherine Litalien, Andrea Gilpin and Sophie Bérubé have each received contract funding from Rare Disease Therapeutics (US), Pharmascience Inc (Canada), Leon NanoDrugs (Germany), and Ethypharm (Canada). No other competing interests were declared.

\section{Address correspondence to:}

$D^{r}$ Catherine Litalien

CHU Sainte-Justine

3175, chemin de la Côte-Sainte-Catherine

Montréal QC H3T 1C5

e-mail: catherine.litalien.hsj@ssss.gouv.qc.ca

Funding: This work was funded by the Rosalind \& Morris Goodman Family Pediatric Formulations Centre of the CHU Sainte-Justine. The Goodman Pediatric Formulations Centre is funded by the Morris \& Rosalind Goodman Family Foundation and CHU Sainte-Justine Foundation. The Goodman family owns Pharmascience. At the time of the study, Julie Autmizguine was receiving salary support from the Fonds de recherche du Québec-Santé (FRQS).

Acknowledgements: The authors would like to thank Ahmadreza Sedighi (data extraction) and Qile Wu (simulation) for their valued input on this project. 